DOI: https://doi.org/10.24297/jssr.v14i0.8134

\title{
Silence as Communication: A Phenomenological Study of Cervical Cancer Patients and Caregivers in Kenya
}

\author{
Jerop Caren ${ }^{1 \star}(\mathrm{MSc})$ Kibiwott Kurgat² $(\mathrm{PhD})$ and George Mose $^{2}(\mathrm{PhD})$ \\ ${ }^{1}$ Alupe University College, P.O Box 845 Busia \\ ${ }^{2}$ Kisii University, Nairobi Campus, School of Information, P.O Box 408-40200
}

\begin{abstract}
Managing a serious diagnosis is a complex and challenging process thus effective communication is a critical aspect of cancer management. However, this has not been given the much needed emphasis. This study therefore sought to examine the influence of communication on cancer management. It adopted an interpretivist research paradigm which is a qualitative approach. It employed the phenomenological method to obtain data from cervical patients and their caregivers. Specifically, a range of in-depth interviews and observations were used to collect data from eight patients and eight caregivers purposively sampled within Uasin Gishu County. Data from the interviews were then analyzed thematically and presented in narrative form using paraphrases and quotations. Ethical issues such as informed consent, confidentiality and official authorization were observed at all levels. The findings of the study indicated that the patients and caregiver downplayed their feelings so as to protect themselves and their loved ones. Social cultural factors and stigma also contributed to their silence. It is concluded that silence is draining and patients and caregivers need to be encouraged by medical practitioners, family and the support groups to share their feelings. Based on the findings of this study, it is necessary for the patients and caregivers to have a platform where they will be able to share their experience.
\end{abstract}

Keywords: Communication, cervical cancer patients, caregiver, silence.

\section{Background}

Communication is a central human process that enables individuals to receive and interpret health issues. Talks about illness experience lie at the very core of such a support system. In specific talks about cancer, patients express their fears as well as fighting strategies in a bid to conquer ill health. However, communicating cancer has not been easy as it is coupled with conversational dilemmas, thus health professionals are reluctant to engage patients in conversations (Maguire et al 1996). Furthermore, some patients are unwilling to voice out illness experience, (Wagstaff, 2014), and medical personnel pitching exclusion - inclusion decisions on some issues in communicating cancer while confining their talks to medicalized contexts (Hordern and Street, 2007).

The awareness of a possibly shortened life and dying fluctuates from suspended awareness or denial, uncertainty, partial or ambiguous awareness, to active and open awareness (Johnston \& Abraham, 2000). Patients also commonly try to "calculate the odds" to judge the appropriateness of being optimistic or hopeful, and "play the odds" to portray prognostic information in a relatively favourable light (Thorne, Hislop, Kuo, \& Armstrong, 2006).

The cancer illness experience is intimately tied to individual patients, but its problematic issues as a public health concern extend to national, continental and global scales. In Kenya for example, cancer is ranked as the third cause of deaths after infectious and cardiovascular diseases (Daily Nation, February 3, 2015). This mirrors the case for Africa, where cancer is emerging as a major public health problem. Africa's continental burden is documented by the International Agency for Research on Cancer (IARC), which cites about 715,000 new cancer cases and 542,000 cancer deaths that occurred in 2008 in Africa (GLOBO-CAN, 2008). These numbers are projected to nearly double (1.28 million new cancer cases and 970,000 cancer deaths) by 2030 owing to aging and growth of the population, with the potential to be even higher because of the adoption of behaviors and 
lifestyles associated with economic development, such as smoking, unhealthy diet, and physical inactivity (WHO 2008). Even with this statistics cancer prevention and support services are still limited in developing countries (Bradleya et al 2005),

Not understanding fully the problems and meanings that cancer holds for people can impede effective care of that person (Houldin, 2000). Moreover, patients suffering from different kinds of cancers have issues that are more specific, or even unique to their status in relation to how it is communicated. Through illness narratives, patients "give voice to suffering in a way that lies outside the domain of the biomedical voice" and "discover new ways to talk about" and deal with the illness themselves as cancer patients (Geist \& Dreyer, 1993, as cited in Anderson \& Martin, 2009, p. 134). In addition, illness narratives are powerful, as they can be utilized to study not only medicine, but the experience of the illness and "its social and cultural underpinnings" (Hydén, 1997). There is need to provide a vehicle for communicating the concerns of cancer patients. Cancer narratives show that the word cancer causes fear and confusion, and arouses an image of painful and inescapable death. The various social misjudgments are one of the greatest challenges to all cancer patients. Therefore, diagnosed persons must carefully choose how, when and with whom they share their cancer experience.

Cancers of cervix and breast are the leading type of cancer among women. The case of cervical cancer stands out as the untold story in communicating cancer, because the cervix is 'part of the body you don't speak about' (Daher, 2012), making its diagnosis to be more distressing than with other cancers (ibid, p. 66-69). Interestingly, controversy surrounds talks about other cancer types as well. For instance, Baralt and Tracy, (2012) give the example of anti-abortion proponents veiling breast cancer advocacy with abortion politics. However, cervical cancer carries an extra load of being a highly stigmatized illness. A study on African American and Caucasians indicated that patients with cervical cancer were significantly more distressed than patients with breast cancer (Lyons \& Shelton, 2004). Its nature, beliefs around causality and the treatment modalities involved also contribute in making it hard for the cervical cancer patients and the family members to talk about. This stigma could be from either the patient or the family members and it is through communication that this could be avoided. Proper choice of words and timely communication is necessary to avoid causing more harm. According to Groome (2006), ineffective communication can cause more harm to the patients.

Given the unvoiced space surrounding cervical cancer, this paper explored a new direction in health communication, studying specific cases of communicating cervical cancer in Kenya, uncovering illness experiences as narrated by patients and their caregivers. Health communication has continuously received significant interest resulting in it being allocated a chapter in the United States of America (USA)'s Healthy People 2010 objectives, demonstrating its growing importance (Parrott, 2004). This clearly shows the relevance of communication to health and well-being of an individual particularly with regard to diseases prevention, health promotion and the general well-being of the population.

According Paal (2011), identifying ways in which cancer patients can express themselves through verbalization process is paramount since narrative becomes an act that breaks the silence on an individual level thus telling of personal experiences becomes meaningful. Good communications can improve outcomes for patients and their families by promoting shared decision making and addressing patient concerns (Pantilat, 2009), while poor communication may harm patients by leading to unwanted intrusive procedures, resulting in unnecessary anxiety or creating feeling of abandonment (Wagstaff, 2014). Yet little has been done to document the experiences of cancer patients, as well as, establish open channels of communication that can enable caregivers understand what patients go through, in addition to establishing effective communications channels to support patients coping with stressors (Sue Blake, Brian Ruel, Clare Seamark \& David Seamark 2007).

When patients begin to verbally express their life and concerns as a cancer patient, conversations about cancer become particularly important (Gibbs \& Franks, 2007). It is therefore necessary to understand how these patients make sense of the world once they realize they are suffering from cancer. Consequently, it is important for people living with cancer to be provided with a platform where they can express their feelings and 
experiences. Caregivers on the other hand being the secondary patients, they need social and psychological support which can only be offered effectively if their experiences are understood.

However, direct communication may not always be possible. Patients and the caregivers may use other strategies to cope with the situation. This can bring communication dilemma and burned which may in turn affect the quality life of the patient and the caregiver. This study therefore sought to understand other coping strategies used by patients and caregiver in cervical cancer management.

The findings of this study contribute to the scanty literature on the experiences of cervical cancer patients, particularly in low resource settings. This study further provides vital insight into understanding the realities cervical cancer patients face on daily basis.

\section{Theoretical approach}

\section{LUUUTT Model}

The LUUUTT model. LUUUTT is an acronym for stories Lived; Unknown stories, Untold Stories, Unheard stories, stories Told, and story Telling. The concept of the tension between stories lived and stories told is familiar to many systemic practitioners. Stories lived are the co-constructed patterns of joint-actions that we and others perform; stories told are the explanatory narratives that people use to make sense of stories lived. Although most people feel the need to align stories lived and stories told, they cannot be identical, and the tension between them provides the dynamic for much of our lives. We might say that people live in such a way as to call into being those stories that they love, need, or want, and to prevent the realization of those stories that they hate or fear. It is also true to say that people tell stories in such a way as to make the events of their lives coherent.

But the tension between stories lived and told is not sufficient to guide us to the potential richness of any given communication pattern. In addition, there are unknown stories which the participants are not (currently) capable of telling; untold stories which the participants are perfectly capable of telling but have chosen not to (at least, not to some of the others in the situation); and, unheard stories which, although they have been told, have not been heard by some important participants in the situation. We suspect that a spiraling evolutionary process works, so that unheard stories become untold stories, and untold stories become, after a while, unknown stories, and vice versa.

The focus of the LUUUTT model is the manner of storytelling, the tensions between and among the story told, the story lived, and or the various "U"s: the untold, unheard, unknown, untellable stories. The LUUUTT model helps the cancer care giver deepen his or her cancer patient's self-reflection thus enriching their relationship by increasing trust and opening up new paths of exploration. As the dialogue continues both individuals deepen their self-awareness and broaden possible opportunities to address their originally stated goals for the relationship.

\section{Materials and methods}

This was a qualitative study employing phenomenological method. Qualitative methodologies seek to understand, and give voice to, complex concepts relating to human experiences and realities (Windle, 2006). The purpose of qualitative research is to position the researcher in the world of the participant (Chase, 2005). Data is produced through contact with people in their own environment and encouraging them tell their story in their own words in an attempt to understand their personal experiences via the analysis of the rich indepth data that this research method produces (ibid). Fundamental to phenomenology was the desire to understand the lived experience from the perspective of the person experiencing it (Patton; 2002). This methodology is concerned with eliciting an account of the individual's perception of an event or experience, as opposed to developing or constructing an objective statement of the event (ibid). Indepth interview was used to get information from eight cervical cancer paients and eight caregivers from Uasin Gishu county, Kenya. Using 
face to face interview allows the researcher a chance to explore the meaning respondents attach to their experiences (Richards, 2003) as well as to observe non-verbal cues and appropriately react or modify his inquiry in response to non-verbal cues (Yin, 2003) of respondents particularly when they elicit confusion, uncertainty, or waning motivation. In analysing the interview data, we used a series of procedures proposed by Hycner (1985) which he recommends specifically for phenomenological studies. The steps included 1) Transcription 2) Bracketing and the phenomenological reduction 3) Listening to the interview for a sense of the whole, 4) Delineating units of general meaning. 5)Delineating units of meaning relevant to the research question. 6) Training independent judges to verify the units of relevant meaning.6) Eliminating redundancies, 7) Eliminating redundancies 8) Clustering units of relevant meaning 9) Determining themes from clusters of meaning. 10). Writing a summary for each individual interview 11). Return to the participant with the summary and themes;12). Modifying themes and summary. 13). Identifying general and unique themes for all the interviews;14) Contextualization of themes.

\section{Findings}

The study found various strategies or ways to patients employed to cope with the reality of being diagnosed with terminal illness. We found a consistent pattern of maladaptive strategies especially those who had recently been diagnosed they avoided any talks that relate to cancer. Over time isolation was felt by both the patients and the caregivers. Silence and masking the truth was a strategy applied to protect the loved ones.

\section{Avoidance}

The respondents were yet to find the courage to talk about it. They evaded talking about it. For such instances, patients are likely to resort to maladaptive strategies of coping with tension, like keeping to themselves, and maintaining dead silence about their experiences.

This is in a bid to cushion their loved ones from emotional and possibly financial burdens that come with the reality of terminal illness diagnosis. Patients' responsive actions of restricting exposure to distressing information has potential benefit of protecting loved ones from feeling and having to take significant action. These untold stories in other cases drain the patient.

...every time I looked at my children I felt pity because I knew I was going to leave them and tears could just roll down my cheeks. This bothered them and they thought I was in pain. I did not want them to know what I was suffering from because I did not want to burden them. Even as we speak, they do not know and I do not want them to know. I always tell them it is back pain. Just wondering for how long I will hide this but ffor now, I am not ready to disclose this information.

To other patients they thought it was Sexual transmitted disease and they did not want to share with anyone. Buying drugs across the counter became a norm though the pain could not subside. This even affected their love life leading to strained relationship. To others the smelly body discharge has made them to be loners.

"About three years ago, I noticed that I had a problem when I had sex with my husband because I would feel a lot of pain. It made me to be angry with my husband because I thought he had infected me with a sexually transmitted infection. Initially I used to persevere but when I couldn't bear it anymore I decided to go to hospital where diagnosis was made. Though my husband is supportive I have a feeling he is seeing another lady. Men can't stay without sex and this is something private you can't discuss with anyone". (Respondent 5)

In a situation where the family caregiver was way younger that the patient, cultural mores would block some conversational topic on cervical cancer. It would seem totally inappropriate to talk about some details about the patient's treatments and ailments. Thus communication between the patient and younger family caregivers often times tended to silence. 


\section{Masking the truth}

Non-action, manifested through resignation and passivity is also a response to patient diagnosis. Patients become completely detached or distanced from any concern relating to actions towards their well-being as relates to diagnosis. In communicating her illness journey, one patient admitted to distortion of facts about her ailment, so as to reduce the size of the threat she is faced with. When she re-interprets the threat, in her view, it reduces the threat's power.

I have not yet told anyone exactly what problem I have. In our culture, this type of illness is termed as a curse, so I usually say I have headache when am going to the hospital to avoid many questions". (Respondent 1)

Close family members also found themselves in similar situations in general conversations with the patient about their wellbeing. They had to downplay the severity of the disease, in response to patient's frequent questions. The story of survival in cervical cancer borders on the unknown, and invites silence to become an untold story. One of the caregivers said it is wrong to affirm to a patient that they are critically ill; it is like telling them they are going to die. Even when you feel sorry about their state, you have to modulate it and just encourage them. This situation brings an ethical dilemma since you feel you really want to say the truth but you are not sure if it will be beneficent or you will be causing harm to the patient. One of the ethical principles, veracity, is about telling the truth. In this situation, it may be a bit challenging, thus the ethical dilemma.

"Every time she asked about death, I lacked words to convince her otherwise. At hospice, I met other caregivers who also faced similar questions from their patients, and did not know how to go about it. I had to say all would be well. There are even occasions I would lie about a noticeable positive improvement on their well-being, yet this was non-existent. In the morning, I could just tell her you are looking bright today. Being in this situation it is devastating and I feel guilty that I have had to lie. (Caregiver 5)

\section{Balancing emotions}

The reality of disease experience or progress becomes an untold story, given the view of truths as brutal to patient emotions. The story told remains with diagnosis, and the untold bit in disease progress closely intertwines with the unheard story of cancer and the unknown story too. Caregivers need to be prepared to answer tough questions, especially with a focus on post-diagnosis disease progress. To do this, they should know what their own feelings and thoughts are, about the situation. This will guide them in unpacking the untold bits about patient progress in conversations with both the diagnosed and their loved ones. With such knowledge, caregivers will be able to show children and other family members how to hope for the best while preparing for and accepting that their loved one may die.

Just like the patients, the caregivers were in the same situational context of making meaning of the newly diagnosed cancer cases. It was worse for late stage diagnosis, since this was a typically an unheard, unknown and untold story to caregivers. The task given on caregiving was overwhelming, trying to create conversations on a topic they barely understood, or unspoken as defined by depressing cultural, linguistic or social imperatives. Now, the caregiving role would require countering assumptions that could be misleading about cancers, as portrayed in cultures or social structures.

"See how caregivers lose their weight, not because of lack of food but due to stress. We provide support without complaining. We never have time to rest or even eat well. Reaction from the patient at times 
can be worrying, especially when they refuse to talk or to take medicine. The caregiver suffers the most, and sometimes this goes unnoticed by many people" lamented caregiver 6 .

This situation is similar to other caregivers. They echoed the fact that they got overwhelmed- taking over the responsibilities, initially done by the patient in addition to theirs. Whenever they take a break from caregiving duties, they are haunted by feelings of guilt owing to may be the inability to share information or give the best care to the patient.

Caregivers often times struggled with an influx of new emotions. They would be affected greatly by changes in a patient's mood. They were worried the perceived futility of treatment. They shared a patient's agony, hurt, discomfort and pain. This ever-changing state equates them to secondary patients. Most could not find stability in addressing patient concerns in conversation. They on few occasions try to avoid face-to-face encounters with patient, and they would not know how to save face in conversational dilemmas. Caregivers were more sensitive to talks on disease diagnosis, causes, and treatment plans and would express varied emotions when addressing the issues. For instance, they would be pained when they realized that a patients' disease had progressed to an advanced staged. They would also be distressed to watch their patient in pain. The caregiving experience often slapped them with negative emotions, and they had to deal with it as they found out ways of taking care of the patients as well. At times, it was difficult coming out of some emotional state they were deeply engorged in, if need arises to attend to other patient's needs. A caregiver admitted that she often had to work with bruised emotions. This made her to attend to her caregiving duties just as routine procedures, because she felt there was nothing much that she could give with a wounded spirit. The influx of emotions would lead them to have a resigned attitude in work, leaving everything to fate.

\section{Isolation}

The caregivers felt ignored by the family members who visit or stay with the patient. They nit-picked when the patient is taken to hospital, they are left behind yet they could even explain to the doctor how the patient has been coping or even take a break from the environment. When back from the hospital, they are not informed about the progress, comments from the doctor or even prepare them on what to expect. The patients also felt isolated by the family members in decision-making. The children made decisions about her treatment without consulting her. This was done to protect her, but it ended on hurting her.

One of the caregivers was in sobs, detailing how her mother's late stage diagnosis took toll on her emotionally. She was the only daughter, and her mother was her confidant. She enjoyed mother-daughter conversations, which just faded when her mother was diagnosed with cervical cancer. She used to seek advice and consolation from her mother in their pre-diagnosis conversations, and this was not possible seeing her mother vulnerable. Seeing her in pain from terminal illness, meant that her world had just come crumbling down. In her conversation, she self-confessed seeking counselling not because she really needed but because she just found everything overwhelmingly depressing. In addition, she could not trust the family members, so she needed an independent person who would not have prejudice and would be supportive. It was difficult to see the positive out of a situation so abrupt, which required a lot of effort in countering the depressing side.

\section{Discussion}

The story of survival in cervical cancer borders on the unknown, and invites silence to become an untold story. Therefore, the reality of disease experience or progress becomes an untold story, given the view of truths as brutal to patient emotions. The story told remains with diagnosis, and the untold bit in disease progress closely intertwines with the unheard story of cancer and the unknown story too.

Diagnosis of cancer which is stories told was noted to be able to alter unknown and unheard cancer stories to patient and family awareness. The view that cancer is an unknown story, an untold story, makes it almost certain that one will be rejected by the community due to misunderstanding of its cause. 
Patients desired that their families and caregivers come out of the experience unharmed emotionally or by financial burdens. In Kenya, cancer treatment is costly, and poses a heavy financial burden to families. Once diagnosed, patients were wary of the trouble they would give their loved ones in meeting financial costs of the disease. Also, they hid their emotions to save face so that loved ones would not be pained at their agony in illness. On the other hand, families get worried at the vulnerability of their loved ones. They are sad to see their loved ones lethargic and in pain, and are at a loss of how to go about conversations that would uplift the fighting spirit of their cancer warriors. Cancer scare silently lives in daily conversations. It manifests in taboo topics, fear to burden loved ones with emotional pain, fear of seeing a loved one vulnerable, and fear relating to awareness of mortality. Silences thus cripple conversations about illness experiences for cervical cancer patients. Both patients and caregivers agreed that positive thinking can be used to cope in such instances.

The fear of communicating pain, makes patients unable to share critical information with their families, care givers and loved ones. It also silences many conversations, which could offer some sense of relief for both patients and their caregivers. A patient centered health communication process should be sensitive to pains as experienced in chronic illness.

Stigma has also contributed to the silence of many patients and caregivers. In some of the communities, those suffering from cervical cancer were perceived to be immoral and isolated in the society. This is due to lack of knowledge on what exactly causes cervical cancer.

Caregivers managing terminally ill patients do suffer a lot and most of them would rather suffer than to add pain to the patient or the family. The pain of these caregivers has always gone unnoticed. Over time, the caregivers lose weight; isolate themselves from the other family members because of low self-esteem while others get withdrawn completely from the world they have known. They desire to die because they feel neglected, unloved and valueless in the society. These changes sometimes are overlooked and the damage in the end is regrettable.

The urge for sex goes down, the pain intolerable. The body discharge makes women to perceive themselves as unclean. The men on the other end desire their conjugal right to be fulfilled. This results to the conflict in the family which at times cause separation leading to divorce.

\section{Conclusion}

Silence can be a window of miscommunication. It is never a solution to the pain experienced. The patients and caregivers will always be drained and the esteem goes down. Through the findings of this study, it will be reassuring to the newly diagnosed patients and the caregivers who are staring the fear-provoking journey to understand that through open communication with others they will be able to manage their worries and anxiety. It is good to note that they are not alone in the journey and there are other who have walked through the cervical cancer path and they have had a positive attitude and perception which has greatly improved their management.

This study therefore recommends sensitization on the power of sharing experiences on cervical cancer management to the public.

\section{Reference}

1. Anderson, J. O., \& Martin, P. G. (2003). Narratives and healing: Exploring one family's stories of cancer survivorship. Health Communication, 15(2), 133-143.

2. Bradleya, J. T., Baronea, M., Mahe'b, C., Lewisc, R., \& Lucianid, S. (2005). Delivering cervical cancer prevention services in low-resource settings International Federation of Gynecology and Obstetrics: Elsevier Ireland Ltd. 
3. Chase, S. E. (2005). Narrative inquiry: Multiple lenses, approaches, voices. In Denzin, N. K. \& Lincoln, Y. (eds.) The Sage Handbook of Qualitative Research. 3rd ed, pp 651-679. Location: Publisher.

4. Daher, M. (2012). Cultural beliefs and values in cancer patients. Annals of Oncology, 66-69. doi: 10.1093/annonc/mds091.

5. Ferlay, J., Shin, H.R., Bray, F., Forman, D., Mathers, C.D., Parkin, D., \& GLOBO-CAN (2008). CancerIncidence and Mortality Worldwide: IARC Cancer-Base No.10 [Internet]. Lyon, France: International Agency for Research on Cancer. 2010; Available from: http://globocan.iarc.fr.2.

6. Globocan, H. (2008). "Globocan 2008 database: summary tables by cancer". Available at http://www.globocan.iarc.fr/. [Accessed on 2015 April 17].

7. Hycner, R. H. (1985). Some guidelines for the phenomenological analysis of interview data. Human Studies, 8, 279-303.

8. Hydén, L. (1997). Illness and narrative. Sociology of Health and IIIness, 19(1), 48-69.

9. Pantilat SZ. (2009) Communicating with seriously ill patients: better words to say. JAMA. 301(12):1279-81.

10. Parrott, R. (2004). Emphasizing "Communication" in Health Communication. Journal of Communication, 54: 751-787. doi: 10.1111/j.1460-2466.2004.tb02653.

11. Patton, M. Q. (2002). Qualitative research \& evaluation methods (3rd ed.). Thousand Oaks: Sage Publications.

12. Thorne, S., Hislop, G. T., Kuo, M., \& Armstrong, E.-A. (2006). Hope and probability: Patient perspectives of the meaning of numerical information in cancer communication. Qualitative Health Research, 16, 318-336.

13. Van Manen, M. (2014). Phenomenology of Practice: Meaning-Giving Methods in Phenomenological Research and Writing. California: Left Coast Press.

14. World Health Organization (2008). World Cancer Report 2008. Lyon: Inter-national Agency for Research on Cancer. 